\title{
Follow-up loss in smoking cessation consultation: can we predict and prevent it?
}

\author{
Bruno Miguel Oliveira Cabrita ${ }^{1 \wedge}$, Maria-Antónia Galego ${ }^{2}$, Ana-Luísa Fernandes $^{1}$, Sara Dias $^{1}$, \\ Sílvia Correia ${ }^{1}$, Paula Simão ${ }^{1}$, Jorge Ferreira ${ }^{1}$, Joana Amado ${ }^{1}$ \\ ${ }^{1}$ Pulmonology Department, Hospital Pedro Hispano, Matosinhos, Portugal; ${ }^{2}$ Pulmonology Department, Hospital de Braga, Braga, Portugal \\ Contributions: (I) Conception and design: BMO Cabrita, J Amado; (II) Administrative support: BMO Cabrita, MA Galego, J Ferreira, P Simão, J \\ Amado; (III) Provision of study materials or patients: All authors; (IV) Collection and assembly of data: BMO Cabrita, MA Galego, J Amado; (V) \\ Data analysis and interpretation: All authors; (VI) Manuscript writing: All authors; (VII) Final approval of manuscript: All authors. \\ Correspondence to: Bruno Miguel Oliveira Cabrita. Praceta António Coelho Figueiredo, $\mathrm{n}^{\circ} 56,4^{\circ}$ Esquerdo Traseiras, $4405-080$ V. N. Gaia, Portugal. \\ Email: bmcabrita@gmail.com.
}

Background: Cigarette smoking has a considerable health and economic burden in modern society, with increased risk of morbidity and mortality. Therefore, smoking cessation policies and medical treatments are essential. However, cessation rates are low and the abandonment of the consultation is common. The identification of characteristics that may predict adherence will help defining the best treatment strategy. This study aimed to identify predictors of follow-up loss in smoking cessation consultation.

Methods: We made a retrospective observational study, including a cohort of patients who started smoking cessation consultation (April-December 2018). Clinical data from consultations was collected and analyzed with IBM SPSS Statistics (SPSS, RRID:SCR_002865).

Results: A total of 175 patients was selected ( $41.1 \%$ female), with a mean age of $53 \pm 12$ years. Eighty-five patients $(48.6 \%)$ were discharged for abandonment. They had a median pack-year unit $38 \pm 36(\mathrm{P}=0.011)$, Fagerström and Richmond scores of $5 \pm 2$ and $7 \pm 2$, respectively. There was an association between women $(\mathrm{P}<0.001)$, younger age $(\mathrm{P}<0.001)$, depression/anxiety $(\mathrm{P}=0.023)$, lower smoking load $(\mathrm{P}=0.019)$, starting the treatment in the first appointment $(\mathrm{P}=0.004)$ and the abandonment of the consultation. In binary logistic regression, younger age (less than 50 years) (OR =4.39; 95\% CI: 1.99-9.70), starting the treatment in the first appointment (OR =3.04; 95\% CI: 1.44-6.42) and depression/anxiety (OR =2.30; 95\% CI: 1.08-4.88) remained independent predictors of loss in follow-up.

Conclusions: Women, younger age, depression/anxiety, lower smoking load and starting treatment in the first appointment are predictors of follow-up loss, so, these patients may benefit from more frequent evaluations and intensive cognitive approach. This study also raises awareness about the adequate timing to start pharmacological support for smoking cessation.

Keywords: Smoking; cessation; treatment; consultation; follow-up

Submitted May 03, 2020. Accepted for publication Feb 22, 2021.

doi: $10.21037 /$ jtd-20-1832

View this article at: http://dx.doi.org/10.21037/jtd-20-1832

^ ORCID: 0000-0002-7832-051X. 


\section{Introduction}

Cigarette smoking represents a considerable health and economic burden in modern society. The risk of mortality is significantly higher in smokers and it has been estimated that smokers die 14 years earlier than never-smokers $(1,2)$. The World Health Organization (WHO) stated that cigarette smoking is the first preventable cause of morbidity and mortality in the world, and is currently considered a chronic disease $(3,4)$. The $\mathrm{WHO}$ also refers that 5 million people die each year due to smoking related diseases, and estimates that the numbers will increase up to 10 million, in 2030 (4). Data from the WHO's 2007 European Tobacco Control Report evidenced that $28.7 \%$ European people smoke, especially man (4).

Nicotine addiction is a multifactorial condition related with neurochemical mechanisms, genetic factors, pathologic background (particularly psychiatric disorders), environmental and also cultural factors (4). The smoking cessation policies are essential to complement medical interventions, which include cognitive and behavioral support, and also pharmacological treatment. However, smoking cessation rates are low, despite all the strategies implemented worldwide, with a higher risk of relapse within the first 6-12 months $(1,3-5)$. Smokers only successfully quit their habits with pharmacological treatment in $20-35 \%$ cases. The success rates are directly related with the combination of cognitive-behavioral and pharmacological treatments, with an individualized approach, involving both the patient and his/her environment (4). Studies report that men have a better long-term outcome than women in this matter, although women smoke less cigarettes and have the same quitting attempts. This is possibly related with less motivation and also the concern of weight gain after quitting smoking habits. Depression and anxiety are associated with failure to quit in female gender, therefore, women require particular attention in the definition of the best treatment strategy $(1,3)$. There is a described association between nicotine dependence and depression and anxiety disorders, probably because smoking is used as a coping mechanism to deal with stress or depressed mood. Depressed smokers are likely to experience more craving and abstinence symptoms, and may benefit from more intense pharmacological treatment and psychological support. Also, smokers with history of depression who quit smoking have increased risk of major depression episodes and relapse (1). Other factors associated with cessation failure are higher nicotine dependence, younger age, poor health and socioeconomic status, greater body mass index and not being married $(2,3)$.

A good adherence to consultations and treatment strategies is essential, but it can be challenging (4). A recent systematic review concluded that $40 \%$ of primary care physicians considers that advising smokers about the benefits of cessation is time-consuming and ineffective, thus, the identification of smoking cessation predictors can be helpful in the management of consultation timing and in the definition of the best individual approach $(1,2)$. Nonadherence to a treatment strategy is a major limitation and a cause of reduced effectiveness $(6,7)$. On the contrary, treatment adherence contributes to better health status of patients, with a direct positive impact in the healthcare system economy $(5,8)$. Some hypothetical reasons for nonadherence are related with the low level of motivation at the time of referral to the intensive approach consultation and the patients' sociodemographic characteristics (5).

The loss of follow-up is one of the main problems in medical studies and interventions, and can reach up to $50 \%$ $(9,10)$. However, it might be minimized with a regular patient contact $(9,11)$. A Portuguese study refers to a dropout rate of smoking cessation consultation of $41.6 \%$, mainly after first appointment. Only few studies analyze the high rates of abandonment of smoking cessation treatment and consultation drop-out, but recognize them as a major multifactorial problem that need more study and understanding (4).

The aiming of this study was to identify predictors of follow-up loss in smoking cessation consultation, which is considered a major understudied issue in healthcare.

We present the following article in accordance with the STROBE reporting checklist (available at http://dx.doi. org/10.21037/jtd-20-1832).

\section{Methods}

\section{Study design}

We made a retrospective observational cohort study. Patients' demographic and clinical information (age, gender, smoking habits, age at smoking initiation, history of previous attempts to quit, pathological background, Fagerström and Richmond scores, stage of behavioral change and treatment strategy) were obtained from medical records and analyzed for comparison.

All patients received the best available care, in accordance with our institutional protocol of smoking cessation consultation, based on national guidelines and recommendations. The protocol included a total of 4-5 presential consultations of 20-30 minutes each, for a year, 
with progressive intervals between consultations ( $2-4$ weeks after beginning treatment, 4-6 weeks during treatment, 36 months reevaluation after smoking cessation). Occasional follow-up phone contacts were also made.

Some patients with significant anxiety and depression disorders were referred to psychology consultation.

The study was conducted in accordance with the Declaration of Helsinki (as revised in 2013). The study was approved by institutional ethics committee and individual consent for this retrospective analysis was waived.

\section{Setting}

The study population included all patients that initiated follow up in smoking cessation consultation, between April 2018 and December 2018 in Pedro Hispano Hospital in Matosinhos (Portugal).

\section{Participants}

Eligible criteria of inclusion in the intensive smoking cessation consultation and, therefore, this study, were: smokers of, at least, 10 cigarettes/day; motivated smokers in preparation stage; patients available for enrolling in the consultation.

Patients' follow-up was made with hospital consultations and phone contacts, according to the clinical situation and phase of smoking cessation process. Follow-up period lasted between April 2018 and June 2019.

Subjects who missed all the appointments were not included in this study.

\section{Variables}

The main outcome of this observational study was to identify predictors of follow-up loss in smoking cessation consultation. The abandonment of the consultation was defined by missing an appointment without requesting a reschedule within 3 months, at least. We considered therapeutic success when patients were able to quit their smoking habits for at least 6 months.

Patients that abandoned the consultation were not considered for the calculation of the success rate.

A patient was considered to have "high educational level" if he/she had a college degree.

"Special D day" defines the day chosen to quit smoking, in association with a special celebration, such as a birthday, for example.

\section{Data sources}

We used our institutional software SClínico and Sistema de Apoio ao Médico (SAM) for consulting patient records and relevant clinical data.

\section{Bias}

The most relevant bias in this study was the subjective measure of smoking cessation medication compliance. Since our institution is not equipped with objective measurement devices for carbon monoxide levels, we relied on patients self-report of treatment compliance, which imply possible bias to our findings.

The selected cohort of this study represents a specific group of patients, referred for intensive smoking cessation approach, in a hospital setting. Therefore, it is not representative of all smokers who attend a general consultation dedicated to smoking cessation.

There was a median 7 months waiting for the first appointment, that, although similar between groups, might have influenced results.

Patients who lost follow-up were not considered to the success rate calculation, despite the possibility of some successful interventions which were not accounted.

\section{Study size}

Our cohort included all patients that initiated smoking cessation consultation in our institution, in the defined period (April-December 2018).

\section{Quantitative variables}

The quantitative variables selected to integrate in this study are key-components of the smoking cessation consultation. We included the following: number of patients, age, smoking load, time for the first consultation, starting age of smoking habits, previous attempts to quit, Fagerström and Richmond scores.

We divided patients in two groups for comparison and better understanding of the differences: the patients that abandoned the consultation and the ones that remained.

\section{Statistical methods}

Statistical analysis was done using IBM SPSS Statistics version 23 (SPSS, RRID:SCR_002865). 


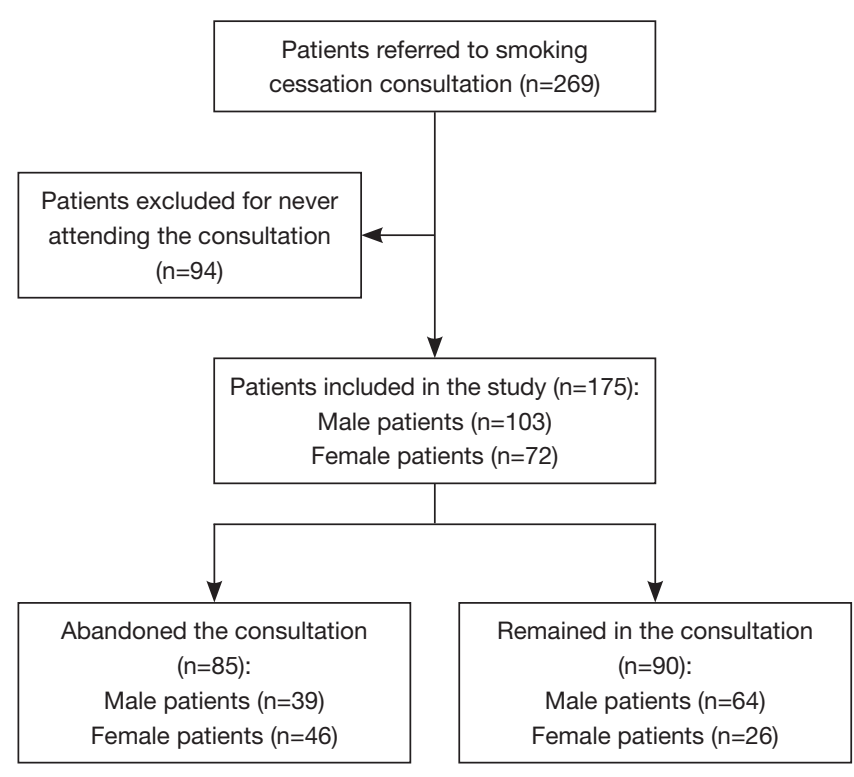

Figure 1 Flow diagram with the study design.

Medians and means were used to compare patients' analytical characteristics. Groups comparison was made with t-tests and Mann Whitney tests, according to the distribution of the variables. Chi-square was used to test associations, comparing categorical variables and determining predictors of follow-up loss. Logistic regression and odds ratio allowed the characterization of independent variables for the determined outcome. A P value of 0.05 or less was considered statistically significant.

Missed data was not included in the analysis and only valid percentage values were used.

Patients that abandoned the consultation were not considered for the calculation of the success rate.

\section{Results}

\section{Participants}

From a population with 269 patients, 94 were excluded for never attending the consultation. Overall, 175 patients were included in this study, selected from smoking cessation consultation between April 2018 and December 2018 (9 months). 72 (41.1\%) patients were women and mean age was $53 \pm 12$ years (Figure 1).

The cohort was divided in 2 groups for comparison of the characteristics: the group that abandoned the consultation and was lost in follow-up, with 85 patients, and the group that remained, with 90 patients (Table 1).

\section{Outcome data}

A total of $85(48.6 \%)$ patients was discharged for abandonment. In this group, there was a higher prevalence of female $(n=46, P=0.001)$ and younger $(48 \pm 18$ years old, $\mathrm{P}<0.001)$ patients. We found an association between patients with less than 50 years-old and the abandonment of the consultation $(\mathrm{P}<0.001)$.

Pathologic background was similar between groups, comparing cardiovascular $(\mathrm{n}=47$ and $62, \mathrm{P}=0.064)$, pulmonary $(\mathrm{n}=30$ and $32, \mathrm{P}=0.971)$, malignant $(\mathrm{n}=11$ and $16, \mathrm{P}=0.376)$ and psychiatric $(\mathrm{n}=7$ and $5, \mathrm{P}=0.483)$ diseases, with the exception of a higher prevalence of anxiety and/or depression in the group that abandoned the consultation, with significant statistical difference ( $\mathrm{n}=40$ and $27, \mathrm{P}=0.023$ ).

Patients lost in follow-up had a lower smoking load, with a median pack-year of $38 \pm 36$ units $(\mathrm{P}=0.011)$. There was a significant statistical association between patients with smoking load inferior than 50 pack-year units and the abandonment of the consultation ( $\mathrm{P}=0.019)$.

Both groups started smoking at approximatively the same age $(15 \pm 4$ and $15 \pm 5$ years-old, $\mathrm{P}=0.889)$, and both had previous attempts at quit smoking $(\mathrm{P}=0.730)$. Also, exposure to other smokers was not significantly different $(\mathrm{n}=31$ and 26, $\mathrm{P}=0.141)$.

Smoking cessation variables were analyzed and compared between the groups (Table 2). Fagerström (mean $5 \pm 2$ and $4 \pm 2, \mathrm{P}=0.322$ ) and Richmond (mean $7 \pm 2$ in both groups, $\mathrm{P}=0.858$ ) scores were similar between groups, representing comparable levels of tobacco dependence and motivation to quit, respectively.

When pharmacological treatment was started in the first appointment, there was a statistically significant difference $(\mathrm{n}=41$ and $25, \mathrm{P}=0.004)$ between the groups, with higher levels of consultation abandonment. The pharmacological treatment choice was not statistically different between the groups and the most frequent treatment was varenicline $(\mathrm{n}=33$ and 32). All the patients were regularly contacted by the medical staff, but only a few responded. In terms of outcome, this approach was not significant $(\mathrm{n}=0.188)$. Success rate was $29.5 \%(n=26)$, excluding the patients lost in follow-up.

\section{Main results}

There was a statistically significant association between women $(\mathrm{P}<0.001)$, younger age $(\mathrm{P}<0.001)$, particularly less than 50 years-old $(\mathrm{P}<0.001)$, the presence of depression 
Table 1 Characteristics of patients that remained and abandoned the consultation

\begin{tabular}{|c|c|c|c|}
\hline Variable & Lost in follow-up & Remained in the consultation & $P$ value \\
\hline Female gender, n (\%) & $46(54.1)$ & $26(28.9)$ & 0.001 \\
\hline Age (years), median [IQR] & $48[18]$ & 58 [13] & $<0.001$ \\
\hline Age $<50$ years old, $\mathrm{n}(\%)$ & $44(51.8)$ & $17(18.9)$ & $<0.001$ \\
\hline \multicolumn{4}{|l|}{ Pathological background, n (\%) } \\
\hline Anxiety or depression & $40(47.1)$ & $27(30.3)$ & 0.023 \\
\hline Other psychiatric disorder & $7(8.2)$ & $5(5.6)$ & 0.483 \\
\hline Malignancy & $11(12.9)$ & $16(17.8)$ & 0.376 \\
\hline \multicolumn{4}{|l|}{ Smoking habits } \\
\hline Starting age (years), median [IQR] & $15[4]$ & $15[5]$ & 0.889 \\
\hline Previous attempts to quit, $\mathrm{n}(\%)$ & $67(80.8)$ & $66(78.6)$ & 0.730 \\
\hline With pharmacological treatment & $13(15.7)$ & $11(13.1)$ & \\
\hline Without pharmacological treatment & $54(65.1)$ & $55(65.5)$ & \\
\hline Pack-year units, median [IQR] & $38[36]$ & $47.5[52]$ & 0.011 \\
\hline Smokers with $<50$ pack-year units, $\mathrm{n}(\%)$ & $58(69.9)$ & $45(52.3)$ & 0.019 \\
\hline Exposure to other smokers, n (\%) & $31(36.9)$ & $26(26.4)$ & 0.141 \\
\hline \multicolumn{4}{|l|}{ Other habits, n (\%) } \\
\hline
\end{tabular}

$I Q R$, interquartile range.

or anxiety $(\mathrm{P}=0.023)$, lower smoking load $(\mathrm{P}=0.011)$, particularly smoking load less than 50 pack-year units $(\mathrm{P}=0.019)$, starting the treatment in the first appointment $(\mathrm{P}=0.004)$ and the abandonment of consultation.

In binary logistic regression of these covariates associated with follow-up loss, younger age (less than 50 years) (OR $=4.39 ; 95 \%$ CI: $1.99-9.70)$, starting the treatment in the first appointment $(\mathrm{OR}=3.04 ; 95 \% \mathrm{CI}: 1.44-6.42)$ and the presence of depression and/or anxiety $(\mathrm{OR}=2.30$; 95\% CI: 1.08-4.88) remained as independent predictors of loss in follow-up in smoking cessation consultation (Table 3).

\section{Other analyses}

There was no significant difference in the educational level of both groups $(\mathrm{P}=0.763)$.

Patients had similar alcohol ( $\mathrm{n}=20$ and $31, \mathrm{P}=0.250)$ and drug consumption history ( $\mathrm{n}=5$ and $2, \mathrm{P}=0.242$ ).

The selection of a special date to quit smoking (special D day) had similar frequency in both groups ( $\mathrm{n}=4$ and $5, \mathrm{P}=1)$.

Patients who remained in the consultation typically showed a progressive reduction of their cigarettes consumption before quitting, however, there was no significant statistical difference between groups $(n=43$, $\mathrm{P}=0.080$ ).

\section{Discussion}

In Portugal, there is a higher prevalence of male smokers, however, women are increasing their smoking habits (4). 
Table 2 Smoking cessation treatment comparison between patients that remained and that abandoned the consultation

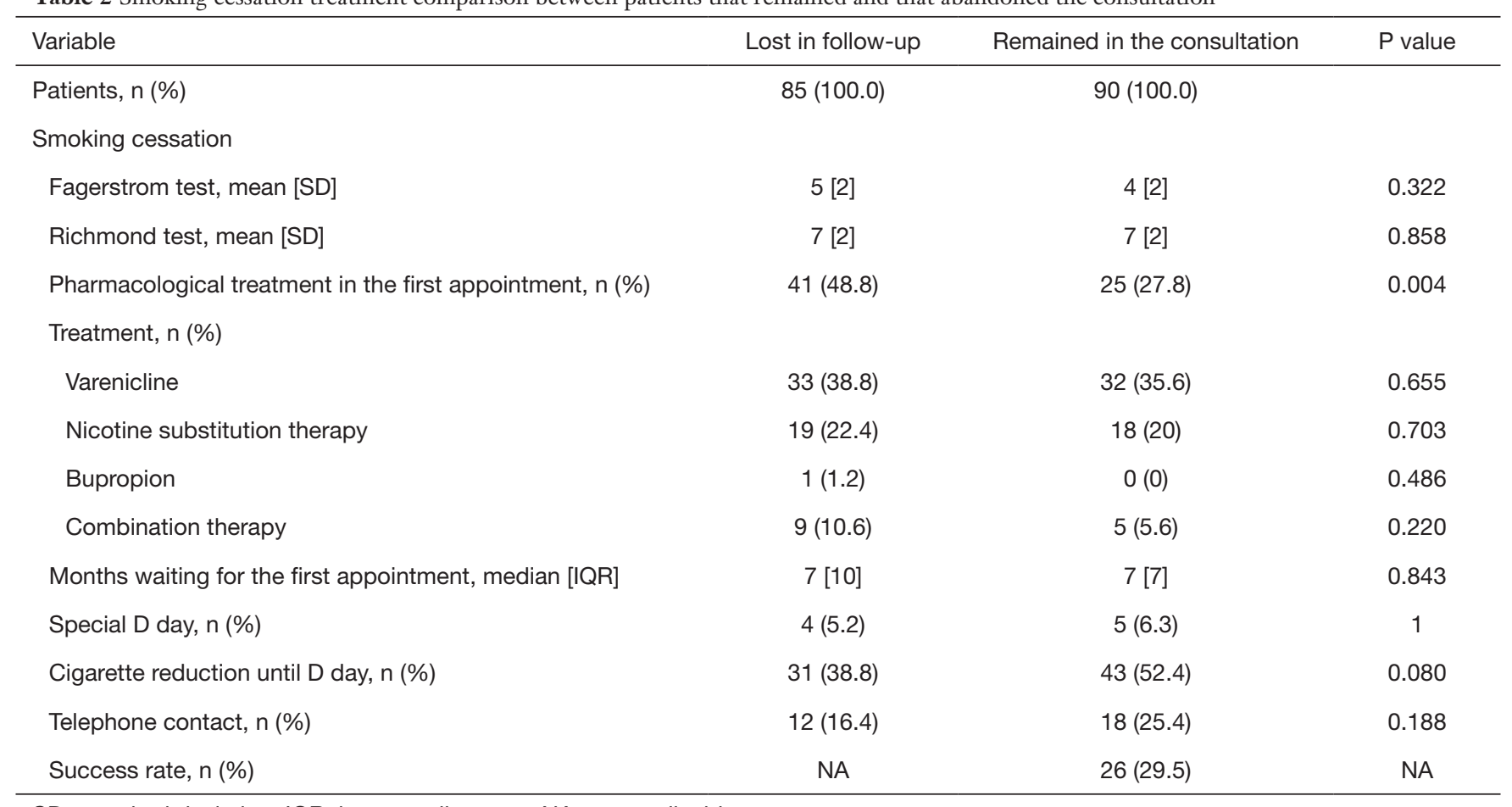

SD, standard deviation; IQR, interquartile range; NA, not applicable.

Table 3 Binary logistic regression of important covariates associated with loss in follow-up

\begin{tabular}{lccc}
\hline Variable & Sig. & OR & \multicolumn{1}{c}{$95 \% \mathrm{Cl}$} \\
\hline Age $<50$ years old & $<0.001$ & 4.397 & $1.993-9.699$ \\
Female gender & 0.175 & 0.596 & $0.282-1.259$ \\
Depression/anxiety & 0.030 & 2.297 & $1.082-4.880$ \\
Smoking load $<50$ PYU & 0.875 & 1.062 & $0.504-2.239$ \\
Starting treatment in the first appointment & 0.004 & 3.041 & $1.441-6.419$ \\
\hline
\end{tabular}

Sig., significance; OR, odds ratio; Cl, confidence Interval; PYU, Pack-Year-Units.

When the cohort was divided for analysis, we found that the group of patients lost in follow-up had higher prevalence of women $(n=46,54.1 \%, P=0.001)$. There was a significant difference between the age of both groups in this study, and we found that younger age (less than 50 years old) is a risk factor for the abandonment of the consultation. We can only infer that this is possibly related with the psychological burden of regular hospital appointments and treatment. From our perspective, the banalization of cigarette smoking and vaping products, with easy access and increasing popularity among teenagers, is one of the reasons why smoking is not considered a major health risk factor in young adults. In fact, the lack of health literacy is a worldwide problem that challenges all healthcare professionals delivering the best care to their patients. However, in this study, we found no influence of the educational level of patients in the results.

After analysis of the pathological background of the cohort, we only found influence of anxiety and/ or depression as a major factor contributing to the abandonment of the consultation ( $\mathrm{n}=40$ and $27, \mathrm{P}=0.023$ ). As reported in the literature, there is a relation between these disorders and higher smoking dependence, however, this study evidences that they may also be considered a risk 
factor for loss in follow-up.

In this cohort, the median age of starting smoking was 15 years old, as observed in reports from the WHO (4). At this age, multiple factors influence teenagers to start smoking, including personal and sociodemographic factors, but particularly the impulse for the adoption of problematic behaviors as a mean of social integration and affirmation (12). Both groups had similar previous attempts at stopping their habits and exposure to passive smoking, but these didn't influence the results. We found a relevant difference in terms of smoking load, as patients lost in follow-up tended to smoke less (median pack-year of $38 \pm 36$ units, $\mathrm{P}=0.011$ ) than the patients that remained in the consultation. Other habits including alcohol and drug consuming, although usually associated with cigarette dependence (12), were not different between groups.

Fagerström score represents an objective measuring tool for evaluation of the tobacco dependence (12). In our study, we found mean values of Fagerström score of $5 \pm 2$, in patients lost in follow-up, and $4 \pm 2$ in patients who attended all consultations $(\mathrm{P}=0.322)$. These values represent a low nicotine dependence (12). Richmond test, on the other hand, measures the motivation to quit smoking (12). In this cohort, Richmond scores were similar, with a mean of $7 \pm 2$ $(\mathrm{P}=0.858)$, representing a moderate motivation (13).

In our clinical experience we observed cases where patients already were recently non-smokers, quitting their habits during the waiting time for the consultation, but were experiencing relevant craving symptoms and were at risk for relapsing, and so, for this reason, we initiated treatment in the first appointment in some patients. We found that these patients were more likely to abandon follow-up ( $\mathrm{P}=0.004)$, and were not considered as neither success or failure of the intervention, implying another possible bias to the success rate.

Different first-line pharmacological treatment options included varenicline, nicotine substitutes, bupropion or the combination of different nicotine substitutes. Varenicline combined with other pharmacological treatment lacks evidence and was not used in this study (12). The most used treatment was varenicline $(\mathrm{n}=65,37.1 \%)$, since it is the option associated with the best results (12). We found no difference in the results considering different pharmacological treatment strategies.

Overall success rate was $29.5 \%$, excluding patients that abandoned the follow-up.

We also aimed at finding whether a selection of a special D day was relevant to the results of the intervention.
However, we found no significant difference between groups. Many patients were able to progressively reduce their consumes until D day, but with no difference between groups. Phone calls were also not an important factor for keeping patients in the consultation.

In this cohort, we found significant independent factors associated with the abandonment of the consultations, including younger age (less than 50 years) $(\mathrm{P}<0.001)$, starting the treatment in the first appointment $(\mathrm{P}=0.004)$ and the presence of depression and/or anxiety $(\mathrm{P}=0.023)$. Other significant factors identified were women $(\mathrm{P}<0.001)$ and a lower smoking load $(\mathrm{P}=0.011)$. Although an understudied issue, preventive measures might include more regular hospital appointments and combination therapy (pharmacological and psychological support) in all high-risk patients for follow-up loss $(1,9,11)$.

Two main reasons associated with clinical relevance of this study may be: first, the loss in follow-up is a major underestimated issue among clinical day practice, including clinical trials, consultations or treatments, with important risks for patients' health, comorbidities control and increased healthcare costs; second, to our knowledge, this is the first article dedicated to analyze the follow-up loss in smoking cessation consultation.

The major limitation of our study may be related with the cohort, since it is not representative of all smokers who attend a consultation to stop smoking, but only a restrict population referenced for intensive smoking cessation approach, in a hospital setting. Also, there was a median 7 months waiting for the first appointment, although similar in both groups, that may have influenced results.

We believe these results may help guide future approaches of smoking cessation consultation in our institution and others with similar practice, and perhaps, stimulate the validation of the research and preventive strategies in other healthcare centers, with larger prospective studies.

\section{Conclusions}

The abandonment of smoking cessation consultation is a frequent and major problem, therefore, we aimed to review our institutional clinical cases and search for characteristics associated with the loss in follow-up. We found that younger patients, history of depression or anxiety disorders were more likely to abandon the consultation, as well as patients with treatment initiated in the first appointment. Other risk factors for the loss in follow-up included female gender and a lower smoking load. This specific group of 
patients may require a different approach and benefit from more frequent evaluations and intensive cognitive therapy. Also, the study results may aware physicians about adequate treatment timing, on an individual basis. More data and studies in this field are required and lacking in the literature.

\section{Acknowledgments}

Funding: Financial Support for the Article Processing Charge, by the Medical Company D’Ar Saúde.

\section{Footnote}

Reporting Checklist: The authors have completed the STROBE reporting checklist. Available at http://dx.doi. org/10.21037/jtd-20-1832

Data Sharing Statement: Available at http://dx.doi. org/10.21037/jtd-20-1832

Conflicts of Interest: All authors have completed the ICMJE uniform disclosure form (available at http://dx.doi. org/10.21037/jtd-20-1832). All authors report article processing charge payment support from D'Ar Saúde, during the conduct of the study.

Ethical Statement: The authors are accountable for all aspects of the work in ensuring that questions related to the accuracy or integrity of any part of the work are appropriately investigated and resolved. The study was conducted in accordance with the Declaration of Helsinki (as revised in 2013). The study was approved by institutional ethics committee and individual consent for this retrospective analysis was waived.

Open Access Statement: This is an Open Access article distributed in accordance with the Creative Commons Attribution-NonCommercial-NoDerivs 4.0 International License (CC BY-NC-ND 4.0), which permits the noncommercial replication and distribution of the article with the strict proviso that no changes or edits are made and the original work is properly cited (including links to both the formal publication through the relevant DOI and the license). See: https://creativecommons.org/licenses/by-nc-nd/4.0/.

\section{References}

1. Caponnetto P, Polosa R. Common predictors of smoking cessation in clinical practice. Respir Med 2008;102:1182-92.

2. Holm M, Schiöler L, Andersson E, et al. Predictors of smoking cessation: A longitudinal study in a large cohort of smokers. Respir Med. 2017;132:164-9.

3. García-Rodríguez O, Secades-Villa R, Flórez-Salamanca L, et al. Probability and predictors of relapse to smoking: results of the National Epidemiologic Survey on Alcohol and Related Conditions (NESARC). Drug Alcohol Depend 2013;132:479-85.

4. Aguiar M, Todo-Bom F, Felizardo M, et al. Four years' follow up at a smoking cessation clinic. Rev Port Pneumol 2009;15:179-97.

5. Pawlina MM, Rondina RC, Espinosa MM, et al. Abandonment of nicotine dependence treatment: A cohort study. Sao Paulo Med J 2016;134:47-55.

6. Usherwood T. Encouraging adherence to long-term medication. Aust Prescr 2017;40:147-50.

7. Smithson H, Horne R, Benson J, et al. Medicines adherence: involving patients in decisions about prescribed medicines and supporting adherence (CG76). NICE 2019.

8. Castro S, Lam H, Sabaté E, et al. Section II: Improving adherence rates: guidance for countries. In: Adherence to Long-Term Therapies - Evidence for Action. WHO; 2003: 32-57.

9. Biant L, Eswaramoorthy V, Field R. How to find patients who are "lost to follow-up". Ann R Coll Surg Engl 2010;92:98-101.

10. Silva AP, Greco M, Fausto MA, et al. Loss to follow-up in a cohort of HIV-negative men who have sex with men: Project Horizonte. Rev Saude Publica 2017;51:60.

11. Campbell RT, Willox GP, Jhund PS, et al. Reporting of Lost to Follow-Up and Treatment Discontinuation in Pharmacotherapy and Device Trials in Chronic Heart Failure: A Systematic Review. Circ Heart Fail 2016;9:e002842.

12. Nunes E, Candeias A, Mendes B, et al. Cessação Tabágica: Programa-tipo de actuação. Lisboa: Direcção Geral da Saúde/Gradiva; 2008.

13. Richmond RL, Kehoe LA, Webster IW. Multivariate models for predicting abstention following intervention to stop smoking by general practitioners. Addiction $1993 ; 88: 1127-35$.

Cite this article as: Cabrita BMO, Galego MA, Fernandes AL, Dias S, Correia S, Simão P, Ferreira J, Amado J. Follow-up loss in smoking cessation consultation: can we predict and prevent it? J Thorac Dis 2021;13(4):2331-2338. doi: 10.21037/jtd-20-1832 